\title{
Is serum citrulline measurement clinically useful in coeliac disease?
}

Emanuela Miceli · Nicoletta Poggi •

Antonio Missanelli · Paola Bianchi •

Remigio Moratti · Gino Roberto Corazza

Published online: 8 July 2008

(C) SIMI 2008

Erratum to: Intern Emerg Med

DOI 10.1007/s11739-008-0155-x

Unfortunately, the article was published under the wrong section. The section should be IM - ORIGINAL.

The online version of the original article can be found under doi:10.1007/s11739-008-0155-x.

E. Miceli · A. Missanelli · P. Bianchi - G. R. Corazza ( $\square)$

First Department of Medicine,

Fondazione IRCCS Policlinico San Matteo,

University of Pavia, Piazzale C. Golgi 19,

27100 Pavia, Italy

e-mail: gr.corazza@smatteo.pv.it

E. Miceli

e-mail: emanuelamiceli@libero.it

N. Poggi · R. Moratti

Department of Clinical Chemistry,

Fondazione IRCCS Policlinico San Matteo,

University of Pavia, Pavia, Italy 